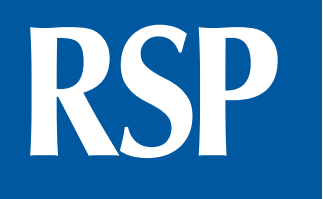

http://www.rsp.fsp.usp.br/

Revista de Saúde Pública

\title{
Socioeconomic status and family functioning influence oral health literacy among adolescents
}

\author{
Roanny Torres Lopes' (iD, Érick Tássio Barbosa Neves' (iD, Laio da Costa Dutra' (iD, Monalisa \\ Cesarino Gomes' (ID, Saul Martins Paiva" (ID, Mauro Henrique Nogueira Guimarães de Abreu" (iD), \\ Fernanda Morais Ferreira" iD, Ana Flávia Granville-Garcia"lı iD \\ 1 Universidade Estadual da Paraíba. Programa de Pós-Graduação em Odontologia. Campina Grande, PB, Brasil \\ " Universidade Federal de Minas Gerais. Faculdade de Odontologia. Departamento de Odontopediatria e \\ Ortodontia, Belo Horizonte, MG, Brasil \\ III Universidade Estadual da Paraíba. Faculdade de Odontologia. Departamento de Odontologia. Campina \\ Grande, PB, Brasil
}

Correspondence:
Ana Flávia Granville-Garcia
R. Baraúnas, 351, Bairro
Universitário, CEP: 58429-500,
Campina Grande (PB), Brasil.
Email: anaflaviagg@gmail.com

Received: Jun 20, 2019

Approved: Aug 22, 2019

How to cite: Lopes RT, Neves ETB, Dutra LC, Gomes MC, Paiva SM, Abreu MHNG, Ferreira FM, Granville-Garcia AF. Socioeconomic status and family functioning influence oral health literacy among adolescents. Rev Saude Publica. 2020;54:30.

Copyright: This is an open-access article distributed under the terms of the Creative Commons Attribution License, which permits unrestricted use, distribution, and reproduction in any medium, provided that the original author and source are credited.

\section{ABSTRACT}

OBJECTIVE: Evaluate socio-demographic, family and behavioral factors associated with oral health literacy (OHL) in adolescents.

METHODS: Cross-sectional study conducted with adolescents aged 15 to 19 years in Campina Grande, Brazil. Parents/guardians answered a questionnaire addressing socio-demographic data. The adolescents answered validated instruments on family cohesion and adaptability (family adaptability and cohesion evaluation scale), drug use (alcohol, smoking and substance involvement screening test), type of dental service used for last appointment and OHL (Brazilian version of the Rapid Estimate of Oral Health Literacy in Dentistry). Two dentists were trained to evaluate $\mathrm{OHL}(\mathrm{K}=0.87-0.88)$. Descriptive analysis was performed, followed by Poisson regression analysis $(\alpha=5 \%)$. A directed acyclic graph was used to select independent variables in the study.

RESULTS: The following variables remained associated with better OHL: high mother's schooling level ( $\mathrm{RR}=1.07 ; 95 \% \mathrm{CI}$ : 1.03-1.12), high income ( $\mathrm{RR}=1.04$; 95\%CI: 1.01-1.09), white ethnicity/skin color $(\mathrm{RR}=1.05$; 95\% CI: 1.01-1.10), married parents ( $\mathrm{RR}=1.04 ; 95 \% \mathrm{CI}$ : $1.01-1.09)$, "enmeshed" family cohesion ( $R R=1.21$; $95 \% C I$ : $1.12-1.30)$, "structured" ( $R R=1.06$; $95 \% C I$ : $1.01-1.12)$ or "rigid" ( $\mathrm{RR}=1.11$; 95\%CI: 1.04-1.19) family adaptability, having more than five residents in the home $(\mathrm{RR}=1.07$; $95 \% \mathrm{CI}: 1.01-1.14)$ and having used a private dental service during the last appointment (RR $=1.08$; 95\%CI: $1.03-1.13)$.

CONCLUSION: Family functioning and socio-demographic factors influence the level of oral health literacy among adolescents.

DESCRIPTORS: Adolescent. Self-Care. Family Relations. Health Education. Dental. Oral Health. Socioeconomic Factors. 


\section{INTRODUCTION}

Oral health literacy (OHL) is the ability to understand and interpret information on dental care to maintain good oral health. Thus, OHL has been associated with oral health-related behaviors and dental outcomes ${ }^{1}$. However, a direct association between oral problems and OHL has not yet been consolidated in the literature ${ }^{2}$. This association is believed to be influenced by other aspects that act as intermediary factors in the process.

The Rapid Estimate of Adult Oral Health Literacy (REALD-30) was designed as a screening tool for individuals with low OHL in different contexts. The Brazilian version (BREALD-30) has proven to be reliable, is easy to administer and has good psychometric properties for use on adults ${ }^{3}$ and adolescents ${ }^{4}$ in the country.

Previous studies on OHL have prioritized adults or evaluated the OHL of parents/guardians associated with oral problems in children (proxy measure) ${ }^{5}$, leaving a gap in the OHL's literature regarding adolescents.

Adolescence is characterized by the pursuit of greater autonomy in making health-related decisions and a decrease in adult supervision ${ }^{6}$. Described as an "index age" by the World Health Organization, the age range between 15 and 19 years of age is considered a target population for epidemiological studies? This is the first study to evaluate the influence of family functioning and social status on OHL among middle to late adolescents. Low OHL levels are believed to impact oral health behaviors and contribute to disparities in access to oral health services. ${ }^{1}$. Thus, family functioning and social aspects need to be better understood to support oral health strategies aimed at this specific age group.

Inappropriate health behaviors, drug use and risk behaviors are common in adolescence. Substance use is associated with lower decision-making capacity and greater probability of inappropriate behavior, making individuals in this phase vulnerable to health problems ${ }^{8}$. Thus, substance use is believed to influence the level of OHL in adolescents.

Other important aspects that can affect OHL are the quality and structure of family relations and the type of dental service used. Appropriate family functioning is known to favor the learning process and academic performance ${ }^{9}$ and may therefore be associated with OHL. Moreover, the quality of care offered at dental services and communication with a dentist varies among the different types of services ${ }^{10}$, which can influence the OHL's level.

Among socioeconomic factors, family income has influenced the academic performance of adolescents ${ }^{11}$. As socioeconomically underprivileged adolescents may exhibit a low level of literacy, it is important to study the association between social class and OHL.

Therefore, this study aimed to evaluate associations between the level of oral health literacy and socio-demographic aspects, family characteristics and behavioral factors in a school-based representative sample of adolescents. To learn the factors associated with OHL in adolescents is important in improving health-related communication and achieving better oral health.

\section{METHODS}

\section{Study design and sample}

This study was conducted in Campina Grande, a center of technological and industrial development in northeast Brazil, despite its worrisome social problems ${ }^{12}$. An analytical, cross-sectional study was conducted at schools in the city with adolescents aged between 15 and 19 years, who were selected using a two-stage sampling process. First, 32 schools (16 public and 16 private) were randomly selected from a total of 131 schools in the city. Next, adolescents were randomly selected through probabilistic sampling (simple random sampling method) to compose a sample proportional to the population of each of the 
city's administration districts. The sample size was calculated considering probabilistic cluster sampling for complex samples, $95 \%$ significance level, 5\% acceptable margin of error, $50 \%$ prevalence rate and 1.6 factor for the design effect. The sample was then increased to compensate for a possible $20 \%$ dropout rate. Thus, the final sample comprised 769 adolescents.

\section{Eligibility criteria}

Adolescents between the ages of 15 and 19 enrolled at public and private schools in the city were included in the study. We excluded individuals with physical, sensory, mental or behavioral limitations according to educators' reports.

\section{Theoretical training and calibration exercises}

OHL was measured using the BREALD-30. Two examiners were trained by an expert in the field, stablishing both inter-examiner and intra-examiner agreement ${ }^{13}$. First, theoreticalpractical training with criteria for the administration of the BREALD-30 was performed, and the results were compared between examiners and expert for the determination of interexaminer agreement using the Kappa statistic $(K=0.87-0.88)$. During the calibration phase, the examiners watched 15 videos of individuals with different levels of OHL and attributed scores to each case. Intra-examiner agreement was calculated by comparing the results of an initial evaluation with the repetition of the evaluation after a seven-day period $(\mathrm{K}=$ 0.87-0.89). The results were compared to those of the expert and discussed.

\section{Pilot study}

A pilot study was conducted with 50 students (25 from a public school and 25 from a private school) to test the applicability of the methods and make any necessary adjustments. The results of the pilot study revealed that no changes to the proposed methods were needed. The adolescents who participated in this step were not included in the main study.

\section{Data collection}

A socio-demographic questionnaire was sent to the parents/guardians via the adolescents to collect the following data: adolescent's sex, self-declared ethnic background, number of residents in the home, position in the family, family income, mother's schooling level and parent's/guardian's age. The parents/guardians needed to be literate and the data collection period was October 2016 to July 2017. The adolescents were also asked about type of dental service (public or private) used for their last appointment.

The Brazilian Economic Classification Criteria ${ }^{14}$ were used to categorize the families into economic classes based on the education level of the head of the household and the number of consumer goods reported by the parents/guardians, such as washing machine, freezer, DVD player, personal computer, dish washer, microwave oven, refrigerators, motorcycles and automobiles (ABEP - Brazilian Association of Research Firms, 2015). Scores were attributed to each item and the sum total was used to classify the families into Class A (45 to 100 points), Class B1 (38 to 44 points), Class B2 (29 to 37 points), Class C1 (23 to 28 points), Class C2 (17 to 22 points) and Class D/E (0 to 16 points).

The validated Brazilian version of the Rapid Estimate of Adult Literacy in Dentistry (BREALD30) was used to measure the OHL of the adolescents. This instrument is used to determine word recognition capacity. The adolescents were asked to read thirty words related to dentistry in increasing order of difficulty ${ }^{4}$. Each correctly pronounced word was awarded one point. The total was then obtained, with higher scores denoting a higher level of OHL.

The Family Adaptability and Cohesion Evaluation Scale (FACES III) developed by the University of Minnesota, whose use was validated in Brazil ${ }^{15}$, was administered to the adolescents to evaluate family functioning. FACES III comprises 20 questions to which the respondent marks one of five response options ranging from "hardly ever" (1 point) to "almost 
always" (5 points). The scores obtained by the sum of odd numbered questions indicate the type of family cohesion and those obtained by the sum of even numbered questions indicate the type of family adaptability ${ }^{16}$.

Family cohesion regards the emotional ties that unite family members and can be classified as "disengaged" (very low cohesion, greater distancing and independence among family members), "separated" (low to moderate cohesion, family members share some activities), "connected" (moderate to high cohesion, greater sharing of activities and greater interest in family ties) or "enmeshed" (very high cohesion, greater emotional dependence with a focus on family relations). Family adaptability regards the capacity family members have to adjust to changes in the family dynamics, being classified as "rigid" (very low adaptability, the family follows the rules of a single member and no changes occur in family roles), "structured" (low to moderate adaptability, more sharing of roles), "flexible" (moderate to high adaptability, more flexibility in terms of family control and rules) or "chaotic" (very high adaptability, no defined functions or leadership) ${ }^{17}$.

Drug use was evaluated using the validated Brazilian version of the Alcohol, Smoking and Substance Involvement Screening Test (ASSIST) developed by the World Health Organization $^{18}$, comprised of eight questions that address the frequency of psychoactive drug use, difficulties in performing daily activities, difficulty interrupting drug use and concerns on the part of parents/guardians. For the present study, we considered answers to the use of legal substances (tobacco and alcohol) and illegal substances (marijuana, cocaine, stimulants, opioids, sedatives, inhalants and hallucinogens) for the previous three months.

\section{Statistical analysis}

A directed acyclic graph (DAG) (Figure) was created using the DAGitty software program (version 3.0) to study the relations between the dependent (OHL) and independent variables.

The statistical analyses were performed with the aid of the Statistical Package for the Social Sciences (SPSS for Windows, version 22.0, SPSS Inc, Chicago, IL, USA). Descriptive analysis was performed for the characterization of the sample. Poisson regression analysis with robust variance was used to test associations between the exposure

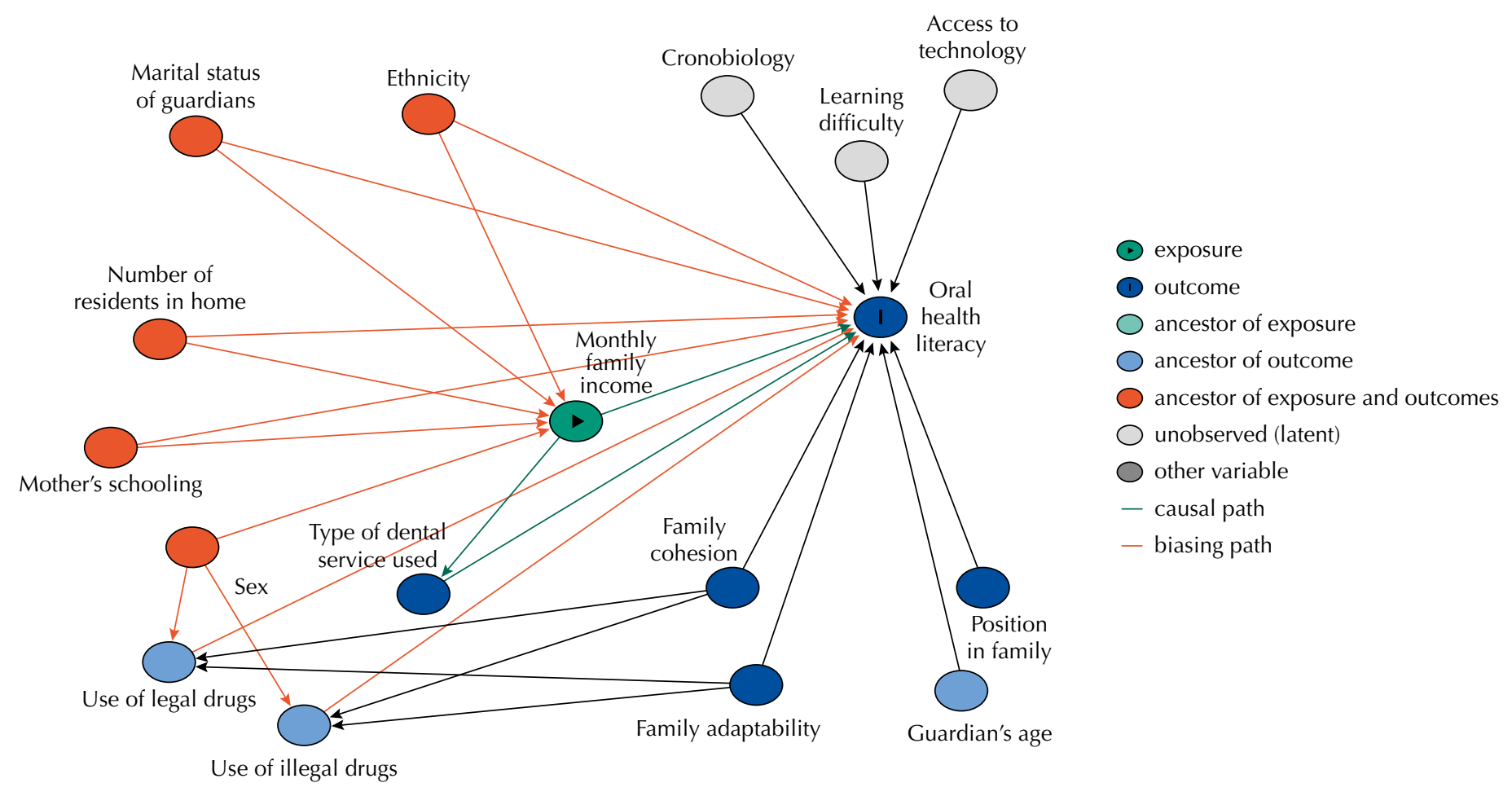

Figure. Directed Acyclic Graph (DAG) for effect of socio-demographic, family and behavioral characteristics on oral health literacy 
variables and outcome. For such, variables with a p-value $<0.20$ in the bivariate analysis were incorporated into the multivariate analysis and those with a $p$-value $<0.05$ in this analysis were kept in the final model. Rate ratios (RR) and 95\% confidence intervals (CI) were calculated for the associations found in both the unadjusted and adjusted statistical models. Oral health literacy was used as a count outcome because cutoff points can vary significantly across populations and there is no standard categorization in the literature. Therefore, for this study, OHL as a count measure was the best way to explore differences between groups.

\section{Ethical aspects}

This study was conducted in accordance with the Declaration of Helsinki and Resolution No. 466/2012 of the Brazilian National Board of Health regarding research involving human subjects and received approval from the Human Research Ethics Committee of the Universidade Estadual da Paraíba (certificate number: 55953516.2.1001.5187).

\section{RESULTS}

The sample comprised 746 adolescents between 15 and 19 years of age. The response rate was $97 \%$. As students from this age group are preparing for important university admission exams, the level of absenteeism was not high. Twenty-three adolescents were excluded for being absent for the interview after three attempts. Table 1 shows the characterization of the sample.

After the adjustments in the multivariate analysis (Table 2), mothers with more than eight years of study had, on average, $7 \%$ higher OHL scores than mothers with eight or fewer years of study. OHL scores were also higher for adolescents from families with a monthly income higher than US\$240, those living in a home with up to five residents, those who declared white ethnicity/skin color, those whose parents were married and those who used private dental services. Adolescents categorized as having "enmeshed" family cohesion had, on average, $21 \%$ higher OHL scores than adolescents with "disengaged" family cohesion. Students with "rigid" or "structured" family adaptability respectively had $11 \%$ and $6 \%$ higher scores than those with "chaotic" family adaptability.

\section{DISCUSSION}

Adolescents with a better socioeconomic status, those who used private dental services and those from families with "enmeshed" type of cohesion and "rigid" or "structured" types of adaptability had better levels of oral health literacy. These results are important, showing, for the first time, factors related to OHL in adolescents. The present findings could contribute to devising public policies directed at this age group. We believe this is the first study to investigate factors associated with OHL in adolescents.

Important associations were found between characteristics of family relations and OHL in adolescents. The association between high family cohesion ("enmeshed" type) and better levels of OHL has also been reported in a previous study, which found that high family cohesion can influence learning levels among children ${ }^{19}$ and that communication between parents and children can affect health-related behaviors in adolescents ${ }^{20}$.

The effect of family adaptability on OHL has not previously been reported. In the present study, adolescents from families with less adaptability ("rigid" and "structured" types) had higher levels of OHL. In such families, authority structure is strict, which may have favored the supervision of the adolescents and contributed to better educational results ${ }^{21}$. Consequently, less family adaptability may have favored greater access to information regarding oral health. 
Table 1. Characterization of sample of adolescents aged 15 to 19 years

\begin{tabular}{|c|c|c|}
\hline Variable & \multicolumn{2}{|c|}{ Percentiles } \\
\hline \multirow{2}{*}{ Oral Health Literacy } & \multicolumn{2}{|c|}{$25,50,75$} \\
\hline & \multicolumn{2}{|c|}{$17,21,24$} \\
\hline \multirow{2}{*}{ Variable } & \multicolumn{2}{|c|}{ Frequency } \\
\hline & $\mathbf{n}$ & $\%$ \\
\hline \multicolumn{3}{|l|}{ Socio-demographic variables } \\
\hline \multicolumn{3}{|l|}{ Sex } \\
\hline Female & 444 & 59.5 \\
\hline Male & 302 & 40.5 \\
\hline \multicolumn{3}{|l|}{ Ethnicity/skin color } \\
\hline White & 211 & 28.3 \\
\hline Non-white & 535 & 71.7 \\
\hline \multicolumn{3}{|l|}{ Type of school } \\
\hline Public & 497 & 66.6 \\
\hline Private & 249 & 33.4 \\
\hline \multicolumn{3}{|l|}{ Monthly family income } \\
\hline$\leq$ US\$ 240 & 272 & 51.0 \\
\hline$>$ US\$ 240 & 261 & 49.0 \\
\hline \multicolumn{3}{|l|}{ Mother's schooling level } \\
\hline$<8$ years of study & 299 & 40.3 \\
\hline$\geq 8$ years of study & 443 & 59.7 \\
\hline \multicolumn{3}{|l|}{ Parent's/Guardian's age } \\
\hline$\leq 42$ years & 384 & 51.6 \\
\hline$>42$ years & 360 & 48.4 \\
\hline \multicolumn{3}{|l|}{ Number of residents in home } \\
\hline$\leq 5$ & 619 & 83.2 \\
\hline$\geq 6$ & 125 & 16.8 \\
\hline \multicolumn{3}{|c|}{ Marital status of parents/guardians } \\
\hline Married & 403 & 54.1 \\
\hline Single, divorced, widowed & 342 & 45.9 \\
\hline \multicolumn{3}{|l|}{ Family/behavioral variables } \\
\hline \multicolumn{3}{|l|}{ Position in family } \\
\hline Oldest child & 314 & 42.1 \\
\hline Middle child & 184 & 24.7 \\
\hline Youngest child & 248 & 33.2 \\
\hline \multicolumn{3}{|l|}{ Use of legal drugs } \\
\hline Yes & 301 & 40.3 \\
\hline No & 445 & 59.7 \\
\hline \multicolumn{3}{|l|}{ Use of illegal drugs } \\
\hline Yes & 54 & 7.2 \\
\hline No & 692 & 92.8 \\
\hline \multicolumn{3}{|l|}{ Family cohesion } \\
\hline Enmeshed & 15 & 2.0 \\
\hline Connected & 121 & 16.2 \\
\hline Separated & 266 & 35.7 \\
\hline Disengaged & 344 & 46.1 \\
\hline \multicolumn{3}{|l|}{ Family adaptability } \\
\hline Rigid & 122 & 16.4 \\
\hline Structured & 216 & 29.0 \\
\hline Flexible & 244 & 32.8 \\
\hline Chaotic & 163 & 21.9 \\
\hline Type of dental service used & & \\
\hline Public & 264 & 40.4 \\
\hline Private & 389 & 59.6 \\
\hline
\end{tabular}


Table 2. Poisson regression for oral health literacy and socio-demographic, family and behavioral characteristics in adolescents aged 15 to 19 years

\begin{tabular}{|c|c|c|c|c|c|}
\hline \multirow{3}{*}{$\begin{array}{l}\text { Variables* } \\
\text { Sex }\end{array}$} & \multirow{2}{*}{$\frac{\text { Oral health literacy }}{\text { Mean (SD) }}$} & \multicolumn{2}{|l|}{ Bivariate } & \multicolumn{2}{|c|}{ Multivariate } \\
\hline & & \multicolumn{2}{|c|}{ Unadjusted Rate Ratio(RR)** } & \multicolumn{2}{|c|}{ Adjusted Rate Ratio(RR) } \\
\hline & & & & & \\
\hline Male & $20.23(5.30)$ & 1.00 & & - & - \\
\hline Female & $20.43(4.89)$ & $1.01(0.97-1.04)$ & 0.597 & - & - \\
\hline \multicolumn{6}{|c|}{ Mother's schooling level } \\
\hline$\leq 8$ years of study & $18.60(5.51)$ & 1.00 & & 1.00 & \\
\hline$>8$ years of study & $21.50(4.35)$ & $1.15(1.11-1.20)$ & $<0.001$ & $1.07(1.03-1.12)$ & 0.001 \\
\hline \multicolumn{6}{|c|}{ Monthly family income } \\
\hline$\leq$ US\$ 240 & $19.11(5.05)$ & 1.00 & & 1.00 & \\
\hline$>$ US\$ 240 & $21.68(4.63)$ & $1.13(1.08-1.18)$ & $<0.001$ & $1.04(1.01-1.09)$ & 0.049 \\
\hline \multicolumn{6}{|c|}{ Parent's/Guardian's age } \\
\hline$\leq 42$ years & $20.09(5.02)$ & 1.00 & & - & - \\
\hline$>42$ years & $20.61(5.10)$ & $1.02(0.99-1.06)$ & 0.163 & - & - \\
\hline \multicolumn{6}{|c|}{ Number of residents in home } \\
\hline$\leq 5$ & $20.68(4.86)$ & $1.09(1.03-1.15)$ & 0.001 & $1.07(1.01-1.14)$ & 0.032 \\
\hline$>5$ & $18.87(5.69)$ & 1.00 & & 1.00 & \\
\hline \multicolumn{6}{|l|}{ Ethnicity/skin color } \\
\hline White & $21.54(5.23)$ & $1.08(1.04-1.12)$ & $<0.001$ & $1.05(1.01-1.10)$ & 0.010 \\
\hline Non-white & $19.88(4.91)$ & 1.00 & & 1.00 & \\
\hline
\end{tabular}

Marital status of parents/ guardians

\begin{tabular}{|c|c|c|c|c|c|}
\hline Married & $20.97(5.02)$ & $1.06(1.03-1.10)$ & $<0.001$ & $1.04(1.01-1.09)$ & 0.040 \\
\hline Single/divorced/widowed & $19.61(5.02)$ & 1.00 & & 1.00 & \\
\hline \multicolumn{6}{|l|}{ Position in family } \\
\hline Oldest child & $20.88(4.91)$ & $1.02(0.98-1.06)$ & 0.240 & - & - \\
\hline Middle child & $19.43(4.71)$ & $0.95(0.91-1.01)$ & 0.057 & - & \\
\hline Youngest child & $20.36(5.41)$ & 1.00 & & - & - \\
\hline \multicolumn{6}{|l|}{ Use of legal drugs } \\
\hline No & $20.26(5.07)$ & 1.00 & & - & - \\
\hline Yes & $20.50(5.04)$ & $1.01(0.97-1.04)$ & 0.526 & - & - \\
\hline \multicolumn{6}{|l|}{ Use of illegal drugs } \\
\hline No & $20.36(5.04)$ & $1.01(0.93-1.08)$ & 0.829 & - & - \\
\hline Yes & $20.20(5.32)$ & 1.00 & & - & - \\
\hline \multicolumn{6}{|l|}{ Гype of dental service used } \\
\hline Public & $19.13(5.06)$ & 1.00 & & 1.00 & \\
\hline Private & $21.50(4.46)$ & $1.12(1.08-1.16)$ & $<0.001$ & $1.08(1.03-1.13)$ & $<0.001$ \\
\hline \multicolumn{6}{|l|}{ Family cohesion } \\
\hline Enmeshed & $24.73(3.36)$ & $1.26(1.17-1.35)$ & $<0.001$ & $1.21(1.12-1.30)$ & $<0.001$ \\
\hline Connected & 21.07 (4.98) & $1.07(1.02-1.13)$ & 0.004 & $1.01(0.95-1.07)$ & 0.727 \\
\hline Separated & 20.79 (4.93) & $1.06(1.02-1.10)$ & 0.003 & $1.03(0.98-1.08)$ & 0.153 \\
\hline Disengaged & 19.57 (5.09) & 1.00 & & 1.00 & \\
\hline \multicolumn{6}{|l|}{ Family adaptability } \\
\hline Rigid & $21.11(5.06)$ & $1.09(1.02-1.16)$ & 0.005 & $1.11(1.04-1.19)$ & 0.001 \\
\hline Structured & $20.81(4.57)$ & $1.07(1.02-1.13)$ & 0.007 & $1.06(1.01-1.12)$ & 0.043 \\
\hline Flexible & $20.24(4.98)$ & $1.04(0.99-1.10)$ & 0.101 & $1.03(0.97-1.10)$ & 0.262 \\
\hline Chaotic & $19.34(5.63)$ & 1.00 & & 1.00 & \\
\hline
\end{tabular}

* Independent variables defined using directed acyclic graph (DAG)

** Unadjusted Poisson regression for socio-demographic, family and behavioral characteristics and oral health literacy among adolescents aged 15 to 19 years

$\mathrm{RR}=$ rate ratio 
High mother's schooling level has been associated with greater OHL among 12-15 years old adolescents, which may be due to the cognitive influence of this variable, as mothers with a higher educational level tend to invest more in their children's education, which affects learning and, consequently, the ability to understand and interpret information ${ }^{22}$. This may explain the association between higher mother's schooling level and higher levels of OHL among the adolescents in the present investigation, the first study to investigate the impact of this variable on the OHL of late adolescents.

The association between family income and OHL has also been reported in a previous study involving parents/guardians of children with dental caries ${ }^{23}$. High family income favors the availability of financial resources and contributes to greater access to dental services and communication with the dentist ${ }^{24}$, possibly contributing to better OHL.

A smaller number of residents in the home was also associated with a higher level of OHL. This finding likely indicates less division of financial resources among family members and the opportunity for greater attention directed at education in families with a smaller number of children ${ }^{25}$, possibly influencing OHL.

Having parents who are married contributed to a higher level of OHL among the adolescents. Children who live with married parents have better psychological maturity, are healthier and receive more attention to their needs, because of greater family support ${ }^{26}$. Therefore, this finding indicates that greater parental support has a positive impact on the level of OHL among adolescents.

White adolescents had better OHL compared with their non-white counterparts. A previous study found that non-white adolescents had a poorer academic performance and called attention to the occurrence of racial difference regarding the academic performance of economically underprivileged adolescent $\mathrm{s}^{27}$. Such social inequalities occur in many societies, affecting the social inclusion of non-white individuals. Moreover, non-white adolescents may have to reconcile work and study due to economic hardship, which has a negative impact on learning capacity ${ }^{28}$, thereby affecting OHL.

Adolescents who used private dental services had better OHL. The high demand for care at public dental services in Brazil and the low priority given to adolescents at such services ${ }^{29}$ may have a negative impact on communication regarding oral health, thereby affecting OHL's levels among adolescents.

No association was found between drug use and OHL, contrary to expectations. A previous study found poorer academic performance and lower concentration among adolescents who took drugs ${ }^{30}$. The absence of an association in the present study likely occurred because only reports of use in the previous three months were considered, which may not represent chronic substance use. Future longitudinal studies should be conducted on the association between OHL and chronic drug use among adolescents. Moreover, since the study was conducted in a school setting, the adolescents may have felt inhibited to declare their actual consumption.

The main limitation of the present study is the cross-sectional design, which does not permit establishing the direction of the associations; longitudinal studies are needed for this purpose. However, this study offers an important indicator of factors associated with OHL in adolescents, which is an under-investigated field of study. The strengths of the study are the methodological care taken in conducting a pilot study, the training/calibration of the examiners and performing two-stage cluster sampling to obtain a representative sample. This study used broad inclusion criteria to represent the target population precisely and enhance its external validity. The results could contribute to devising public policies aimed at the promotion of oral health in adolescence. Such policies should include family evaluations at schools and health services ${ }^{15}$ to assist in preventing problematic oral health behaviors among adolescents. 
Brazilian adolescents with a better socioeconomic status, from families with "enmeshed" cohesion and "rigid" or "structured" adaptability, and those whose parents were married had better levels of OHL. These results underscore the importance of a favorable family environment to better oral health literacy.

\section{REFERENCES}

1. Baskaradoss JK. The association between oral health literacy and missed dental appointments. J Am Dent Assoc. 2016;147(11):867-74. https://doi.org/10.1016/j.adaj.2016.05.011

2. Firmino RT, Ferreira FM, Paiva SM, Granville-Garcia AF, Fraiz FC, Martins CC. Oral health literacy and associated oral conditions: a systematic review. J Am Dent Assoc. 2017;148(8):604-13. https://doi.org/10.1016/j.adaj.2017.04.012

3. Junkes MC, Fraiz FC, Sardenberg F, Lee JY, Paiva SM, Ferreira FM. Validity and reliability of the Brazilian version of the Rapid Estimate of Adult Literacy in Dentistry - BREALD-30. PLoS One. 2015;10(7):e0131600. https://doi.org/10.1371/journal.pone.0131600

4. Lima LCM, Neves ETB, Dutra LC, Firmino RT, Araújo LJS, Paiva SM et al. Psychometric properties of BREALD-30 for assessing adolescents' oral health literacy. Rev Saude Publica. 2019;53:53. https://doi.org/10.11606/S1518-8787.2019053000999

5. Divaris K, Lee JY, Baker AD, Vann WF Jr. Caregivers' oral health literacy and their young children's oral health-related quality-of-life. Acta Odontol Scand. 2012;70(5):390-7. https://doi.org/10.3109/00016357.2011.629627

6. Hoffman S, Rueda HA, Beasley L. Youth perspectives of healthcare in Central Mexico: an application of Massey's critical health literacy framework. Int J Environ Res Public Health.2019;16(5):896. https://doi.org/10.3390/ijerph16050896

7. Ahmad OB, Boschi-Pinto C, Murray CJL, Lozano R, Inoue M. Age standardization of rates: a new who standard. Geneva: WHO; 2001. (GPE Discussion Paper Series, 31).

8. Chisolm DJ, Manganello JA, Kelleher KJ, Marshal MP. Health literacy, alcohol expectancies, and alcohol use behaviors in teens. Patient Educ Couns. 2014;97(2):291-6. https://doi.org/10.1016/j.pec.2014.07.019

9. Kashahu L, Karaj S, Karaj T. Academic achievements of adolescents and family functioning. Acad J Interdiscip Stud. 2016;5(3 S1):157-70. https://doi.org/10.5901/ajis.2016.v5n3s1p157

10. Aldosari MA, Tavares MA, Matta-Machado ATG, Abreu MHNG. Factors associated with patients' satisfaction in Brazilian dental primary health care. PLoS One. 2017;12(11):e0187993 https://doi.org/10.1371/journal.pone.0187993

11. Bae D, Wickrama KAS. Family socioeconomic status and academic achievement among Korean adolescents: linking mechanisms of family processes and adolescents' time use. J Early Adolesc. 2015;35(7):1014-38. https://doi.org/10.1177/0272431614549627

12. Instituto Brasileiro de Geografia e Estatística. Informações estatísticas. Cidades: Campina Grande. Rio de Janeiro: IBGE; c2017 [cited 2018 Oct 29]. Available from: https://cidades.ibge.gov.br/brasil/pb/campina-grande/panorama

13. Vilella KD, Assunção LRS, Junkes MC, Menezes JVNB, Fraiz FC, Ferreira FM. Training and calibration of interviewers for oral health literacy using the BREALD-30 in epidemiological studies. Braz Oral Res. 2016;30(1):e90. https://doi.org/10.1590/1807-3107BOR-2016.vol30.0090

14. Brazilian Market Research Association. Brazilian criteria 2015 and social class distribution update for 2016 [cited 2018 Oct 29]. Available from: http://www.abep.org/criterio-brasil

15. Falceto OG, Busnello ED, Bozzetti MC. [Validation of diagnostic scales of family functioning for use in primary health care services]. Rev Panam Salud Publica. 2000;7(4):255-63. Portuguese. https://doi.org/10.1590/s1020-49892000000400007

16. Olson DH, Tiesel JW. Family Functioning Evaluation Scale (FACES III): fact sheet. Harrisburg, PA: Diakon-Swan; 2014 [cited 2018 Oct 29]. Available from: https://www.diakon-swan.org/swan/documents/item/168/

17. Olson DH, Russell CS, Sprenkle DH. Cicumplex model: systemic assessment and treatment of families. Abingdon (UK): Routledge; 1989. 
18. Henrique IFS, De Micheli D, Lacerda RB, Lacerda LA, Formigoni MLOS, Formigoni MLOS. [Validation of the Brazilian version of Alcohol, Smoking and Substance Involvement Screening Test (ASSIST)]. Rev Assoc Med Bras. 2004;50(2):199-206. Portuguese. https://doi.org/10.1590/S0104-42302004000200039

19. Rezaei-Dehaghani A, Keshvari M, Paki S. The relationship between family functioning and academic achievement in female high school students of Isfahan, Iran, in 2013-2014. Iran J Nurs Midwifery Res. 2018;23(3):183-7. https://doi.org/10.4103/ijnmr.IJNMR_87_17

20. Avdic A, Büyükdurmus T. Communication problems? The role of parent-child communication for the subsequent health behavior of adolescents. Ruhr Econ Papers. 2015;(547):4-34. https://doi.org/10.4419/86788625

21. Shute VJ, Hansen EG, Underwood JS, Razzouk R. A review of the relationship between parental involvement and secondary school students' academic achievement. Educ Res Int. 2011:ID915336. https://doi.org/10.1155/2011/915326.

22. Veerasamy A, Kirk R, Gage J. Oral health literacy of adolescents of Tamil Nadu, India. Sch J Dent Sci. 2016;3(4):112-20.

23. Lai SHF, Wong MKW, Wong HM, Yiu CKY. Parental oral health literacy of children with severe early childhood caries in Hong Kong. Eur J Paediatr Dent. 2017;18(4):326-31. https://doi.org/10.23804/ejpd.2017.18.04.11

24. Davoglio RS, Abegg C, Aerts DRGC. Factors related to the use of dental services among adolescents from Gravataí, RS, Brazil, in 2005. Rev Bras Epidemiol. 2013;16(2):546-54. https://doi.org/10.1590/S1415-790X2013000200028

25. Karwath C, Relikowski I, Schmitt M. Sibling structure and educational achievement: how do the number of siblings, birth order, and birth spacing affect children's vocabulary competences? J Family Res. 2014;26(3):372-96. https://doi.org/10.20377/jfr-2014-26-3

26. Langton CE, Berger LM. Family structure and adolescent physical health, behavior, and emotional well-being. Soc Serv Rev. 2011;85(3):323-57. https://doi.org/10.1086/661922

27. Gordon MS, Cui M. The intersection of race and community poverty and its effects on adolescents' academic achievement. Youth Soc. 2016;50(7):947-65. https://doi.org/10.1177/0044118X16646590

28. Bachman JG, Staff J, O'Malley PM, Freedman-Doan P. Adolescent work intensity, school performance, and substance use: links vary by race/ethnicity and socioeconomic status. Dev Psychol. 2013;49(11):2125-34. https://doi.org/10.1037/a0031464

29. Macarevich A, Pilotto LM, Hilgert JB, Celeste RK. User satisfaction with public and private dental services for different age groups in Brazil. Cad Saude Publica. 2018;33(2):e00110716. https://doi.org/10.1590/0102-311x00110716

30. Chukwu EO, Pius VT, Fiase TM, Haruna H, Terkuma C, Evangeline AC. Effects of substance/drug abuse on the academic achievement of secondary school students in Mkar Metropolis, Gboko, Benue State. Int J Psychol Brain Sci. 2017;2(2):40-5. https://doi.org/10.11648/j.ijpbs.20170202.12

Acknowledgments: The authors are grateful to the State University of Paraiba and the following Brazilian fostering agencies: State of Minas Gerais Research Assistance Foundation (FAPEMIG) and National Council of Scientific and Technological Development (CNPq).

Funding: State of Paraiba Research Assistance Foundation (FAPESQ-PB), 2018, process number: 101/2018; Coordination for the Advancement of Higher Education Personnel (CAPES), 2017, process number: 88887.155389/2017-00.

Authors' contributions: Lopes RT, Neves ETB, Granville-Garcia AF, Ferreira FM, Abreu MHNG, Dutra LC, Gomes MC and Paiva SM participated in the interpretation of the data and writing of the article; Paiva SM, Abreu MHNG, Ferreira FM and Granville-Garcia AF participated in the conception and planning of the study; Neves ETB and Dutra LC collected the data; Gomes MC participated in the interpretation and analysis of the data; Ferreira FM and Granville-Garcia AF performed the revisions of the article; Lopes RT, Neves ETB, Granville-Garcia AF, Ferreira FM, Gomes MC, Dutra LC e Paiva SM approved the final version and assume public responsibility for the content of the article.

Conflict of the Interests: The authors declare that there is no conflict of interest. 